\title{
LEGITIMIDADE E DISTINÇÃO: REFLEXÕES SOBRE A FORMAÇÃO E A ATUAÇÃO DO CONSELHO CONSULTIVO DO SERVIÇO DO PATRIMÔNIO HISTÓRICO E ARTÍSTICO NACIONAL (1938-1966)
}

\author{
LEGITIMACY AND DISTINCTION: REFLECTIONS ON THE \\ FORMATION AND PERFORMANCE OF THE ADVISORY BOARD \\ OF THE SERVIÇO DO PATRIMÔNIO HISTÓRICO E ARTÍSTICO \\ NACIONAL [NATIONAL HISTORICAL AND ARTISTIC SERVICE]
} (1938-1966)

\author{
Leila Bianchi Aguiar ${ }^{1}$ \\ Jamile da Silva Neto ${ }^{2}$
}

RESUMO:A institucionalização das práticas de preservação do patrimônio cultural no Brasil foi marcada pela criação do Serviço do Patrimônio Histórico e Artístico Nacional (Sphan) em 1937. Desde então, a agência de preservação contaria com um Conselho Consultivo, formado, inicialmente, por dez membros eleitos pelo presidente da República e pelos diretores dos museus nacionais históricos e artísticos. Estudar a composição e as práticas de construção de legitimidade e distinção desse Colegiado é uma das formas aqui encontradas para uma compreensão mais ampla dos rumos da política de preservação do patrimônio cultural no Brasil nas três primeiras décadas de atuação do Sphan. Para tanto, foram investigadas as atas das reuniões do Conselho, livros e artigos publicados pelos conselheiros e as Revistas do Patrimônio, publicadas no período.

PALAVRAS-CHAVE: Instituto do Patrimônio Histórico e Artístico Nacional; Iphan; Patrimônio Cultural; Conselho Consultivo; Rodrigo Melo Franco de Andrade.

\footnotetext{
* Este artigo foi desenvolvido como consequência do Trabalho de Conclusão de Curso "O Conselho Consultivo do Sphan: trajetórias e práticas (1938-1966)" de Jamile Silva Neto, orientado pela professora Leila Bianchi Aguiar e da pesquisa de iniciação científica intitulada "Turismo e Preservação do Patrimônio Cultural no Brasil: uma análise do Conselho Consultivo do Iphan (1937-1975)", realizada entre os anos de 2013 e 2015, sob orientação de Leila Bianchi Aguiar e financiada pelo Conselho Nacional de Desenvolvimento Científico e Tecnológico (CNPq).

${ }^{1}$ Professora Associada do Departamento de História, do Programa de Pós-Graduação em História e do Mestrado Profissional em Ensino de História da Universidade Federal do Estado do Rio de Janeiro (Unirio). Email: leila.aguiar@unirio.br

${ }^{2}$ Doutoranda do Programa de Pós-Graduação em História Social da Unirio. Email: jamile.sneto@gmail.com
} 
ABSTRACT: In Brazil, the institutionalization of cultural heritage preservation practices was marked by the creation of the National Historical and Artistic Heritage Service (Sphan) in 1937. Since then, this preservation institute had an Advisory Council, initially composed, by ten members chosen by the president of the republic and by the directors of the national history and artistic museums of the country. Studying the council's distinction, legitimacy, practices and composition was the direction taken to better understand the cultural heritage preservation policies in Brazil during the three first decades of Sphan existence. With that objective in mind, the minutes of the Board meetings, books and articles published by the board members, and the numbers of Revista do Patrimônio, published in the period, were investigated.

KEYWORDS: National Historical and Artistic Heritage Institute; Iphan; Cultural Heritage; Advisory Board; Rodrigo Melo Franco de Andrade

A fundação do Serviço do Patrimônio Histórico e Artístico Nacional (Sphan), em 1937, integrou um projeto mais amplo de construção e modernização da nação pelo governo Vargas (1930-1945). Neste processo, intelectuais de diferentes vertentes do pensamento foram arregimentados para ocuparem cargos na administração pública.

Como abordado em vários estudos sobre as políticas de preservação no Brasil, no período que compreende a gestão do Sphan por Rodrigo Melo Franco de Andrade (1937-1967), foram consolidadas as bases legais que nortearam as ações do Sphan e institucionalizadas as práticas e procedimentos do órgão de preservação (CHUVA, 2009; 2014; FONSECA, 2009; GONÇALVES, 2002; RUBINO, 1991; 1996; SANTOS, 1996). Desse modo, compreende-se o período estudado como fundamental para a definição de ações de seleção e preservação dos bens que seriam constitutivos do patrimônio nacional, sendo por isso, marcado por embates entre diferentes ideias de patrimônio (CHUVA, 2009; FONSECA, 2009; SANTOS, 1996).

No Decreto-lei $n^{\circ}$ 25/37, que organizou o órgão de preservação e deu origem ao tombamento, foram especificadas as atribuições de um Conselho Consultivo para o Sphan. Este seria formado por dez membros eleitos pelo Presidente da República e pelos diretores dos museus nacionais de coisas históricas e artísticas (Sphan, 1980: 107). A inspiração viria do projeto de lei de José Wanderley de Araújo Pinho de 1930 e do anteprojeto de Mário de Andrade 
de 1936, que versaram sobre a criação de um órgão federal de preservação e suas atribuições. ${ }^{3}$ No anteprojeto de Mário de Andrade, o Conselho seria formado por historiadores, artistas plásticos, gravadores, etnógrafos, músicos, pintores, escultores, arquitetos e arqueólogos e os assentos deveriam ser distribuídos entre consultores mais novos (com menos de 40 anos) e mais experientes (mais de 40 anos). Essa proposta marcada, sobretudo, pela grande diversidade profissional acabou sendo suprimida na criação do Conselho Consultivo do Sphan, mantendo-se apenas, no Decreto-Lei 25, a concessão de assentos no Conselho a representantes de instituições científicas e detentores de saberes em áreas específicas. ${ }^{4}$

Dentre as atribuições do Conselho, de acordo com o Decreto-Lei 25 de 1937, estavam as decisões sobre a pertinência dos tombamentos solicitados, julgamento dos processos de impugnação abertos por proprietários contrários ao tombamento de seus imóveis e as autorizações sobre a saída do país de bens móveis tombados. Na reunião inaugural do Conselho Consultivo, realizada em 10 de maio de 1938, Gustavo Capanema, ministro da Educação e Saúde, afirmou que este se constituía "por especialistas de notável competência e de comprovado espírito público"(ATAS, 10 maio 1938). Tal afirmação justificaria o papel decisivo do Conselho e seus membros nas políticas de preservação, uma vez que suas decisões, conforme o Decreto-lei no 25 , eram irrevogáveis. ${ }^{5}$

Estudos realizados por Márcia Chuva, Maria Cecília Londres Fonseca, José Reginaldo Gonçalves, Maria Isabel Lenzi e Mariza Santos que tratam do Conselho Consultivo do Sphan enfatizam as especialidades e reconhecidos saberes de seus membros (CHUVA, 2009; CHUVA, 2014; FONSECA, 2009; GONÇALVES, 2002; LENZI, 2013; SANTOS, 1996). Márcia Chuva (2009) defende que os membros do Conselho faziam parte de uma ampla teia de

\footnotetext{
${ }^{3}$ Ambos os projetos se encontram na obra: SERVIÇO DO PATRIMÔNIO HISTÓRICO E ARTÍSTICO NACIONAL (SPHAN). Proteção e revitalização do patrimônio cultural no Brasil: uma trajetória. Brasília: Mec/Sphan/ Pró-memória, 1980.

${ }^{4}$ Para saber mais sobre as propostas defendidas para o Conselho Consultivo nestes projetos, ver CHAGAS, 2003; CHUVA, 2009; MONTEGRO, 2004; SILVA NETO, 2015.

5 A partir do Decreto-lei 3.866, de 29 de dezembro de 1941, foi permitido ao Presidente da República cancelar tombamentos, todavia, ainda competia ao Conselho Consultivo opinar sobre recursos para cancelamento de bens tombados (BRASIL, 1967).
} 
relações entre notórios integrantes dos campos intelectual e político brasileiros, os quais estavam de algum modo inseridos no Estado. O caráter técnicocientífico foi um dos pilares da estruturação do órgão de preservação brasileiro. Os trabalhos elaborados pelo Sphan deveriam estar afinados com os "modernos critérios científicos" (FONSECA, 2009). Nesse sentido, os agentes autorizados a falar sobre o patrimônio nacional deveriam ser especialistas em seus campos de atuação e seus discursos contribuíram para forjar noções de representação do passado nacional.

\section{Rotinas e práticas do Conselho Consultivo}

Para além das atribuições do Conselho Consultivo previstas no Decretolei $\mathrm{n}^{\circ} 25 / 37$, uma série de práticas foram acordadas na reunião inaugural, realizada no dia 10 de maio de 1938 . Ficou definido que as reuniões ordinárias aconteceriam nas primeiras segundas-feiras úteis de cada mês, às $17 \mathrm{~h}$; enquanto as reuniões extraordinárias seriam convocadas pelo presidente do Conselho ou por solicitação de dois ou mais membros do Conselho (ATAS, 10 maio 1938).

O Decreto-lei $n^{\circ} 25$ não deixou expresso a quem caberia a presidência do Conselho Consultivo. Por isso, na reunião inaugural, Rodrigo Melo Franco de Andrade propôs uma votação para decisão quanto à presidência, mas os conselheiros Gustavo Barroso e Edgard Roquette-Pinto defenderam que o diretor do Sphan deveria ser o presidente do Conselho, não havendo necessidade de votação. Entretanto, Rodrigo Melo Franco de Andrade argumentou que, para o bom andamento das atividades do Conselho, seria conveniente que este não fosse presidido pelo diretor do Sphan, pois as iniciativas e pareceres deste teriam de ser frequentemente julgadas por este órgão colegiado: “[...] tal era o empenho que punha em certas iniciativas tomadas no exercício de suas funções administrativas, que receava constranger o próprio Conselho ao submetê-las a aprovação" (ATAS, 10 maio 1938). Gustavo Barroso defendeu, então, que, para afastar dos debates qualquer circunstância alegada pelo diretor, Rodrigo Melo Franco de Andrade presidiria 
o Conselho, mas não teria o direito de voto, sendo essa proposta aceita por unanimidade. $^{6}$

Na reunião inaugural, foram também definidos os procedimentos para a distribuição dos processos de tombamento. O presidente do Conselho sugeriu que fosse adotado o mesmo método dos tribunais de $2^{\mathrm{a}}$ instância e o modelo de outros conselhos consultivos, qual seria: o presidente distribuiria a um relator o processo de tombamento que deveria emitir voto por escrito na reunião subsequente e os votos dos demais membros do Conselho seriam colhidos logo após a explanação do voto do relator. O presidente levantou também a questão quanto à escolha do relator, cujas opções eram distribuição por sorteio ou a critério do presidente. Decidiu-se que, pelo fato da nomeação dos conselheiros ter sido motivada pelo critério de especialização, a distribuição dos processos de tombamentos se faria a critério do presidente do Conselho. Outra discussão realizada diz respeito à possibilidade ou não dos conselheiros votarem por procuração, ficando decidido que não seriam lícitos votos nesse formato.

Interessante notar que, assim como observa Maria Cecília Londres Fonseca (2009), os conselheiros debatiam questões que não estavam prescritas no Decreto-lei ${ }^{\circ} 25$ e também não estariam, mais tarde, no Regimento Interno de $1946,{ }^{7}$ ou seja, discutiam questões que legalmente transcendiam sua alçada. $\mathrm{Na}$ primeira reunião extraordinária, realizada em 17 de maio de 1938, em função da solicitação realizada por Luiz Kuchembecker do tombamento da Fábrica Patriota, a qual não era sua propriedade (ATAS, 10 maio 1938), suscitou-se a discussão se propriedades de domínio de particulares, da União, dos estados ou dos municípios poderiam receber requerimento de tombamento por parte de qualquer cidadão. Depois de longa discussão, o Conselho deliberou que, apesar do Decreto-lei $n^{\circ} 25$ não prever o tombamento de bens particulares por parte de outro que não seja o seu proprietário, seria considerado lícito o

\footnotetext{
${ }^{6}$ Cabe ressaltar que antes da ponderação do conselheiro Gustavo Barroso quanto à negação do direito de voto do presidente, Manuel Bandeira estava de acordo com as razões alegadas por Rodrigo Melo Franco de Andrade para não assumir a presidência.

${ }^{7}$ A partir do Regimento Interno de 1946 - Decreto-lei $n^{\circ} 8.534$ de 02 de janeiro de 1946 -, dentre outras atribuições, ao Conselho Consultivo competiria ajuizar sobre todos os pedidos de tombamento (BRASIL, 1967).
} 
pedido de tombamento de qualquer bem móvel ou imóvel por todo cidadão, baseando-se nos critérios de interesse público.

Já na sessão ordinária realizada no dia 31 de julho de 1946, Pedro Calmon solicitou a elaboração de plano de obras de reparação, conservação e restauração da cidade de Salvador pelo Sphan, em função da comemoração do quarto centenário de fundação da cidade. A proposta foi aceita unanimemente pelos conselheiros e o presidente do Conselho declarou que providenciaria, com satisfação, a elaboração do plano sugerido (ATAS, 31 jul. 1946). Na reunião ordinária realizada no dia 18 de dezembro de 1957, José Cândido de Mello Carvalho, diretor do Museu Nacional, solicitou que os membros do Conselho o apoiassem na campanha em prol da recuperação da Quinta da Boa Vista. Debatida a matéria, o Conselho Consultivo deliberou dirigir-se ao prefeito do Distrito Federal com objetivo deste tomar as devidas providências no sentido de restauração completa do parque da Quinta da Boa Vista (ATAS, 18 dez. 1957). Podemos afirmar que a reunião de intelectuais ligados a instituições de pesquisa e de memória transformava o Conselho em um lugar privilegiado para a definição dos rumos da política de preservação e ainda de temas mais amplos da cultura brasileira.

Tais intelectuais também acreditavam que o Conselho seria um espaço privilegiado para exercerem seus "espíritos públicos”, expressão frequente desde a reunião inaugural do Conselho (ATAS, 10 maio 1938). O espírito público dos membros seria enfatizado em outras ocasiões, como na reunião ordinária de 14 de junho de 1957, quando Rodrigo Melo Franco de Andrade propõs nota de pesar pelo falecimento de José Wasth Rodrigues, assinalando seu pertencimento ao Conselho por "puro espírito público". Nesse caso, possivelmente, a expressão foi usada para exaltar seu comprometimento e participação no Conselho, sem que houvesse qualquer remuneração financeira. Também na sessão de 24 de setembro de 1959, Rodrigo Melo Franco de Andrade ressaltou a "cultura, inteligência e espírito público"de Thiers Martins Moreira, que havia sido recentemente empossado como diretor da Casa de Rui Barbosa. Serem portadores de "espírito público" relacionava os conselheiros à 
"causa do patrimônio", a qual consistia em empreender todos os esforços para salvar da destruição e esquecimento os bens patrimoniais que representavam a identidade nacional, a identidade, em suma, de todos os cidadãos brasileiros. ${ }^{8} \mathrm{~A}$ ligação à "causa do patrimônio" dos membros do Conselho Consultivo era de suma importância para uma de suas principais funções: formular, ou chancelar, narrativas para o patrimônio nacional em um momento em que "[...] as pessoas tinham de ser persuadidas até mesmo da existência de um patrimônio histórico e artístico brasileiro [...]" (GONÇALVES, 2002: 49).

Vale a pena ressaltar que o Conselho Consultivo foi sistematicamente apresentado, nos discursos de Rodrigo Melo Franco de Andrade e dos conselheiros como uma esfera externa ao Sphan. Como já fora mencionado, o receio de Rodrigo Melo Franco de Andrade em ser presidente do Conselho mostra-se como indício da tentativa de construção dessa diferenciação entre o Sphan e o seu Conselho Consultivo. Conforme o desejo de Rodrigo Melo Franco de Andrade, as decisões do Sphan, coordenadas por ele, não poderiam interferir naquelas tomadas pelo Conselho. Portanto, entende-se a autonomia salientada na ordem do discurso entre Sphan e Conselho Consultivo como o desejo de tornar ilibados os julgamentos proferidos pelos seus membros. Segundo Maria Cecília Londres Fonseca (2009), afirma-se, desde o início, a relação de "autonomia" entre o Conselho e o Sphan.

No Decreto-lei $n^{\circ}$ 25/37, vinculado ao conceito de função social da propriedade garantida pela Constituição de 1934, restringia-se o direito de propriedade a partir do tombamento. Desse modo, a defesa do interesse público sobrepunha-se ao interesse privado (CHUVA, 2009; FONSECA, 2009; RABELLO, 2009). O distanciamento entre o Sphan e seu Conselho Consultivo, defendido por Rodrigo Melo Franco de Andrade e pelos conselheiros, tinha certamente como motivação tornar as decisões do Conselho imunes aos interesses e às decisões dos quadros técnicos do órgão de preservação. Nesse sentido, o caráter de especialização e distinção dos conselheiros conferia

\footnotetext{
${ }^{8}$ José Reginaldo Gonçalves, em seu livro A Retórica da Perda: os discursos do patrimônio cultural no Brasil (2002), faz uma análise dos usos e significação da expressão causa do patrimônio.
} 
legitimidade a tais decisões que definiriam o destino da propriedade privada de cidadãos brasileiros.

Entre 1938 e 1966, 82 processos de tombamento ${ }^{9}$ foram encaminhados para análise pelos membros do Conselho, dentre estes, apenas 28 processos de tombamento representaram algum grau de divergência de opiniões entre os conselheiros. Constata-se, portanto, que mais da metade dos processos julgados seguiu, por unanimidade, o voto dos relatores. Na maioria dos casos, observouse que os relatores dos processos de tombamento embasaram suas decisões nos pareceres dos técnicos e naqueles assinados por Rodrigo Melo Franco de Andrade, ou seja, raras foram as vezes em que um bem foi estudado pelo conselheiro relator (ATAS, 1938-1966). Além disso, Rodrigo Melo Franco de Andrade foi relator, direta ou indiretamente, de processos de tombamento ${ }^{10}$ enquanto presidiu as reuniões. Tal postura do diretor do Sphan mostra o quanto a distinção entre Conselho e órgão de preservação não ocorria na prática. Portanto, a despeito dessa diferenciação entre Conselho e Sphan na ordem do discurso, pode-se perceber que as decisões dos conselheiros pautaram-se, na maior parte das vezes, nos pareceres dos técnicos do Sphan e do diretor do órgão.

Cabe notar, como assinala Lucieni Simão (2008), que "apesar de o Conselho legitimar, na maioria das vezes, a orientação imprimida pelos técnicos do SPHAN, as deliberações só ocorreriam após o assunto ser submetido a calorosas discussões." (SIMÃO, 2008: 52). Nas atas das reuniões desse colegiado, várias vezes são mencionadas longas discussões, mas dessas pode-se extrair apenas a resolução final da matéria debatida. Apesar de, na maior parte dos casos, não ser possível verificar o posicionamento dos conselheiros, pode-

\footnotetext{
${ }^{9}$ Neste número total, estão incluídos os processos de pedido de cancelamento de tombamento de bens e o plano especial de obras em proveito da cidade de Ouro Preto, os quais tiveram relatores e foram debatidos em reuniões do Conselho Consultivo.

${ }^{10}$ Processo $n^{\circ}$ 0203-T-39 (Casa de Pedra, Minas Gerais); processo ${ }^{\circ}$ 0371-T-47 (ruínas do Convento de São Bernardino de Sena, Angra dos Reis); processo no 0063-T-40 e 0223-T-40 (Igrejas e aos Conventos de São Francisco, São Bento e do Carmo, João Pessoa); processo n ${ }^{\circ}$ 0052-T-40 (Igreja da Penha, Rio de Janeiro); processo no 0608-T-60 (Pico de Itabirito, Minas Gerais). Tais processos de tombamento são exemplos em que Rodrigo Melo Franco de Andrade foi diretamente relator ou casos em que a decisão final do Conselho baseou-se no "Parecer do Sphan”, o qual era redigido pelo diretor do órgão.
} 
se afirmar que o Conselho Consultivo foi espaço de discussão sobre as políticas de preservação, porém, havia um modus operandi e certa concepção de patrimônio sendo construída pelos agentes do órgão que se mostrava presente nas decisões do Conselho Consultivo. ${ }^{11}$

Em geral, obedecia-se à seguinte rotina: membros do Sphan ou externos indicavam o tombamento de um bem, o diretor do órgão escolhia um técnico para ir até o local onde o tombamento foi solicitado para que fosse feito um parecer técnico de teor descritivo, ressaltando, principalmente, as características físicas dos objetos. Depois disso, este era encaminhado ao diretor do órgão para o parecer do Sphan, mais argumentativo e propositivo (CHUVA, 2009). Logo em seguida, as solicitações de tombamento voluntárias e as de proprietários impugnantes seriam encaminhadas para decisão do Conselho Consultivo. Segundo o Decreto-lei $n^{\circ}$ 25, não caberia recurso após essa definição. Após o Regimento Interno de 1946, em tese, todos os pedidos de tombamento encaminhados ao Sphan seriam ajuizados pelo Conselho Consultivo.

Os processos de tombamento analisados pelo relator do caso conselheiro escolhido a critério do diretor do Conselho - poderiam receber, após discussão e votação dos membros, as seguintes decisões: "aceito por unanimidade", quando todos concordassem com o voto proferido pelo relator do caso; "aceito por maioria de votos", situação em que um ou mais conselheiros discordassem do voto do relator; "pedido de vista do processo", quando um ou mais conselheiros pedissem para ver o processo de tombamento do bem, para, depois, proferirem seu voto - neste caso, a votação era adiada para a próxima reunião; e, "converter o julgamento em diligência", quando um ou mais conselheiros decidisse estudar melhor o caso em questão, algumas

\footnotetext{
${ }^{11}$ Muitos trabalhos que tratam das primeiras décadas de atuação do órgão de preservação enfatizam a construção de uma dada ideia de patrimônio, ligado ao barroco-colonial, localizado, sobretudo, no estado de Minas Gerais (CHUVA, 2009; FONSECA, 2009; RUBINO, 1991; 1996). Para além dos critérios arquitetônicos valorizados dentro do Sphan, pode-se pensar que, em boa medida, as concepções de história - centradas sobretudo na valorização de grandes eventos e de figuras ilustres - manejadas pelos conselheiros para justificarem o tombamento foram também fundamentais na construção de dada ideia do que representaria o patrimônio nacional. Para saber mais sobre as concepções de história manejadas por intelectuais do Conselho Consultivo, ver SILVA NETO, 2018.
} 
vezes fazendo visitações aos locais onde se encontravam os bens - nestas situações, a votação do caso era adiada para a próxima reunião.

As decisões sobre os casos de tombamento eram tomadas após o debate entre o membro relator e os demais conselheiros. Ao que parece, todos tinham o mesmo direito de fala, no entanto, uns manifestavam-se mais que outros. Além disso, em função dos temas discutidos, algumas vozes foram mais ouvidas e solicitadas que outras. Essas desigualdades necessitam ser analisadas, uma vez que todos os membros do Conselho Consultivo foram eleitos pelo critério de especialização e "notório saber".

\section{Composição e atuaçãono Conselho Consultivo}

Em pronunciamento realizado na reunião inaugural do Conselho Consultivo, Gustavo Capanema afirmou que o critério de escolha dos conselheiros estava baseado no "notório saber" que possuíam. Os membros do Conselho Consultivo eram especialistas, no sentido de possuírem um vasto conhecimento em determinadas áreas do saber, em especial Artes Plásticas, História, Arqueologia, Antropologia, Direito.

Ao mesmo tempo em que o Sphan legitimava-se como o principal órgão responsável pela preservação do patrimônio histórico e artístico nacional, tendo suas decisões referendadas por um Conselho de especialistas, a participação em seu Conselho Consultivo, o qual seria em última instância, responsável pelas decisões relativas à preservação de bens que materializam o passado nacional brasileiro, conferia a seus membros um importante capital simbólico ${ }^{12}$ que, aos poucos, passará a ter maior significado para as redes intelectuais e de sociabilidade em que atuavam. Vale notar que ao mesmo tempo em que o Conselho Consultivo era local de obtenção de visibilidade, ${ }^{13}$ também se mostrava como destino de reconhecidos nomes da intelectualidade brasileira.

\footnotetext{
${ }^{12}$ Definido por Pierre Bourdieu como "uma propriedade qualquer percebida pelos agentes sociais, cujas categorias de percepção são tais, que eles podem entendê-las e reconhecê-las atribuindo-lhes valor". (BOURDIEU, 1996:107).

${ }^{13}$ Para saber mais sobre como o Conselho Consultivo do Sphan foi lugar de visibilidade para alguns intelectuais, ver LENZI (2013) e SILVA NETO (2018).
} 
Os conselheiros eram intelectuais de prestígio em seus campos de atuação e participavam da construção da legitimidade das decisões irrevogáveis quanto ao tombamento, que arbitrava sobre os destinos da propriedade de outrem. Isto é, o tombamento baseia-se na tutela do Estado sobre o patrimônio nacional, sendo "[...] a autoridade técnica a chave da legitimidade da violência simbólica do poder tutelar. [...]" (CHUVA, 2014: 205). Portanto, o Conselho mostrou-se como esfera privilegiada e legítima para definições sobre que bens ou conjuntos urbanos deveriam ser protegidos (CHUVA, 2009; 2014; SANTOS, 1996).

Apesar de ser enfatizada a presença dos intelectuais modernistas nas agências ligadas à cultura durante o Governo Vargas (1930-1945), sobretudo presentes no órgão de preservação do patrimônio (CHUVA, 2009; BOMENY, 1994; 2001; SANTOS, 1996), os membros do Conselho Consultivo não eram majoritariamente ligados às correntes de pensamento modernista. Além disso, a despeito de haver um grupo de intelectuais, sobretudo mineiros, ligados diretamente a Rodrigo Melo Franco de Andrade nos quadros do Sphan ou realizando trabalhos para esse Serviço ${ }^{14}$ (CHUVA, 2009; BOMENY, 1994; 2001;FARIA, 1995), não foram identificados os mesmos laços de amizade entre Rodrigo Melo Franco de Andrade e boa parte dos membros do Conselho. No entanto, a convivência nesse órgão colegiado, a participação nas discussões e os estudos acerca do patrimônio e outros assuntos, provavelmente aproximaram o diretor do Sphan de elementos da intelectualidade do Conselho desse Serviço. Ao longo das reuniões torna-se notória a sua admiração pela trajetória e conhecimento dos conselheiros. Em 1968, em seu discurso de posse no Conselho Consultivo, ${ }^{15}$ Rodrigo Melo Franco de Andrade declarou

[...] fiquei também comovido com a investidura, porque vim substituir aqui meu dileto amigo Miran Latif, um dos mais distintos e influentes membros deste colegiado, autor de livros notáveis pela originalidade da interpretação das

\footnotetext{
14 “[...] Íamos todas as tardes para o escritório do Rodrigo - um trabalhador infatigável - e eu tinha pena dele, porque estávamos sempre lá. Eu não era ninguém face aos outros freqüentadores, pois iam para lá José Lins do Rêgo; Gastão Cruls - também infatigável; Drummond, um funcionário muito discreto; Afonso Arinos, de Minas e primo de Rodrigo; e vários outros intelectuais." (FARIA, 1995: 28).

${ }^{15}$ Após o término de sua direção do Sphan, em 1967, Rodrigo Melo Franco de Andrade integrou, por curto período, o Conselho Consultivo. Tendo falecido no ano de 1969.
} 
ocorrências do passado e do presente do Brasil, abalizado geólogo e mineralogista, engenheiro e arquiteto talentoso, homem de gosto e grande conhecedor do acervo de arte antiga do país, ao qual não faltava, antes impelia sempre, um vibrante espírito público. [...]

Além da lembrança ainda muito viva e dolorida de Miran Latif, ocorre-me igualmente, ao participar pela primeira vez como vogal dos trabalhos deste Conselho, a recordação dos outros seus integrantes que precederam na morte aquele caríssimo companheiro: Raimundo Lopes, Alberto Childe, Rodolfo Siqueira, Roquete Pinto, Marques Júnior e Wasth Rodrigues, todos os quais ilustraram este colegiado e dos quais conservo a memória mais grata. (ANDRADE, 1986:180-1)

Como pode ser observado na tabela em anexo, boa parte dos nomes citados por Rodrigo Melo Franco de Andrade permaneceu no Conselho por longos anos, isto porque a rotatividade de seus integrantes era pouco frequente. O Decreto-lei $n^{\circ} 25$ não trata da questão da renovação dos membros do Conselho Consultivo. Desse modo, os conselheiros foram substituídos, principalmente, em caso de falecimento, aposentadoria ou por não pertencerem mais aos postos de diretores de museus.

Os membros eleitos pelo Presidente da República entre 1938 e 1966 foram o historiador Afonso Arinos de Melo Franco (1938-1987); ${ }^{16}$ o arqueólogo Alberto Childe (1938-1950); o historiador da arte Alfredo Galvão (1958-1984); o historiador Antônio Joaquim de Almeida (1966-1966); o artista Augusto José Marques Junior (1938-1957); o arquiteto Carlos de Azevedo Leão (1938-1938);o antropólogo Edgard Roquette-Pinto (1938-1954); o historiador da arte Francisco Marques dos Santos (1938-1975); o historiador Gilberto Ferrez (1958-1997); o artista José Otávio Corrêa Lima (1938-1974); o jurista José Soares de Mello (1955-1971); o historiador da arte José Wasth Rodrigues (1953-1957); o arquiteto Lucio Costa (1938-1940);o escritor Manuel Bandeira (1938-1968); o arquiteto Miran de Barros Latif (1946-1968); o arquiteto Paulo Santos (1955-1980); o historiador Pedro Calmon (1946-1985); o antropólogo Raimundo Lopes da Cunha (1938-1940); o historiador da arte Rodolfo

\footnotetext{
16 Entre parênteses, encontra-se o período em que os intelectuais ocuparam assentos no Conselho Consultivo.
} 
Gonçalves de Siqueira (1938-1953); e, o museólogo Sérgio Ferreira da Cunha (1960-1960).

Os membros representantes de museus foram: o historiador Alcindo Sodré, diretor do Museu Imperial (1940-1952); o historiador Américo Jacobina Lacombe, diretor da Casa de Rui Barbosa (1947-1992), o escritor Eugênio Gomes, diretor da Casa de Rui Barbosa (1962-1963); o historiador Gustavo Barroso, diretor do Museu Histórico Nacional (MHN) (1938-1959); a antropóloga Heloísa Alberto Torres, diretora do Museu Nacional (1938-1955); o zoólogo José Cândido de Mello Carvalho, diretor do Museu Nacional (19551961); o historiador da arte José Roberto Teixeira Leite, diretor do Museu Nacional de Belas Artes (MNBA) (1961-1964); o escritor Josué Montello, diretor do MHN (1960-1967); o antropólogo Luiz de Castro Faria, diretor do Museu Nacional (1964-1967); o artista Manoel Constantino Gomes Ribeiro (1961-1961); ${ }^{17}$ o naturalista Newton Dias dos Santos, diretor do Museu Nacional (1961-1964); o artista Oswaldo Teixeira, diretor do MNBA (19381961); e, o escritor Thiers Martins Moreira, diretor da Casa de Rui Barbosa $(1959-1960){ }^{18}$

Ao analisar a trajetória de cada membro do Conselho Consultivo, percebe-se a possibilidade de mais de uma classificação profissional em muitos casos. Assim, Afonso Arinos de Melo Franco poderia ser classificado como historiador e jurista, e Miran Latif, engenheiro e arquiteto. Existem muitos outros exemplos de membros que não atuavam em apenas uma área do conhecimento. Desse modo, as classificações profissionais elencadas acima foram geradas em função da análise da documentação sobre eles, isto é, elegeuse a área profissional de acordo com o cotejamento de dados que apontavam para uma área de atuação predominante, a qual convivia e se relacionava com outros campos do conhecimento. Certamente, o fato dos conselheiros serem

17 Manoel Constantino Gomes Ribeiro foi vice-diretor do MNBA, na gestão de Oswaldo Teixeira. Em 1961, ano em que tem fim a gestão deste, Manoel Constantino participou de três reuniões seguidas do Conselho Consultivo. Cabe uma investigação maior para saber se Manoel Constantino assumiu interinamente a direção do museu logo após a saída de Oswaldo Teixeira, tendo José Roberto Teixeira Leite empossado no cargo de diretor do MNBA em 1961.

${ }^{18}$ Informações disponíveis, em anexo, na Tabela de atuação e participação dos membros do Conselho Consultivo do Sphan. 
versados em diferentes saberes conferia ao Conselho maior legitimidade e representatividade.

Diferente dos quadros técnicos do Sphan em que, sobretudo, os arquitetos - alinhados com as correntes de pensamento modernistas - tiveram lugar cativo até a década de 70 (CHUVA, 2009; FONSECA; 2009; SANTOS, 1996), o Conselho Consultivo, como pode ser notado a partir da tabela em anexo, constituiu-se de forma mais heterogênea, integrando-o antropólogos, escritores, historiadores, advogados, artistas, dentre outros. ${ }^{19}$ Todavia, cabe questionar se os campos político-sociais integrados pelos conselheiros eram tão heterogêneos quanto a sua formação acadêmica. Boa parte dos conselheiros havia nascido no Rio de Janeiro ou municípios do estado; muitos deles formaram-se e/ou trabalhavam nas mesmas instituições - Escola Nacional de Belas Artes (ENBA) e Universidade do Brasil. E, por fim, integravam instituições científicas consideradas notáveis, como o Instituto Histórico e Geográfico Brasileiro (IHGB) e a Academia Brasileira de Letras (ABL). A despeito das formações mais diversificadas, houve certas áreas de atuação privilegiadas.

Destaca-se que a heterogeneidade do Conselho foi maior nas suas primeiras décadas, quando foram nomeados especialistas de diferentes áreas do saber, caso do arqueólogo Alberto Childe e dos antropólogos Edgard RoquettePinto e Raimundo Lopes. ${ }^{20}$ Após o falecimento desses membros, não foi

\footnotetext{
${ }^{19}$ Entre 1938 e 1966, o Conselho Consultivo foi composto de maioria absoluta por homens. As exceções foram Heloísa Alberto Torres, diretora do Museu Nacional de 1938 a 1955 , permanecendo no Conselho durante este período; Elza Peixoto Ramos que participou, no período estudado, de algumas reuniões como diretora substituta do MNBA; e, Nair de Moraes Carvalho que participou de uma reunião representando o diretor do MHN. Portanto, de 1938 a 1966, não houve nenhuma indicação pelos Presidentes da República de mulheres para comporem o Conselho Consultivo.

${ }^{20}$ Como notado por Walter Lowande, “o Conselho tinha o Museu Nacional representado de forma majoritária, com quatro membros dessa instituição (a própria Heloísa Alberto Torres, na condição de diretora do Museu Nacional, Edgard Roquette-Pinto, Raimundo Lopes e Alberto Childe)." (LOWANDE, 2018: 428). Desse modo, o autor destaca que, apesar das políticas de preservação terem se centrado no tombamento do patrimônio arquitetônico, os bens de natureza etnográfica e arqueológica também figuraram nessas políticas desde o início dos trabalhos do Sphan, tendo esses intelectuais como representantes dessas temáticas no Conselho (LOWANDE, 2018). Conforme apresentado neste artigo, tais intelectuais, que conferiam em grande medida heterogeneidade ao Conselho, não foram substituídos por outros representantes dessas áreas do conhecimento e tampouco ligados ao Museu Nacional.
} 
indicado pelo Presidente da República um novo conselheiro que atuasse novamente nesses campos do saber. Como pode ser observado a partir da tabela em anexo, no caso dos membros pertencentes ao Conselho Consultivo que possuíam assento cativo pelo fato de dirigirem algum dos museus especificados na Lei $\mathrm{n}^{\mathbf{0}} 378$, cabe notar que, comparados aos demais membros do Conselho, a diversidade de formação mostra-se sensivelmente maior. ${ }^{21}$ No entanto, os conselheiros ligados aos museus não foram nomeados como membros do Conselho seguindo o critério de especialização, mas sim por dirigirem tais instituições.

Ainda atentando para as periodicidades, ressalta-se que os membros que permaneceram por mais tempo dentro do Conselho foram, em sua maioria, aqueles ligados à História e à História da Arte. Ademais, ainda que o Conselho tenha sido constituído por integrantes com especializações mais diversificadas, percebe-se, de acordo com a tabela em anexo, que alguns dos conselheiros possuíam maior espaço de atuação que os demais em função do número de processos relatados. Em suma, é possível apontar uma série de limites à aparente heterogeneidade do Conselho ao serem observadas área de atuação, periodicidades e substituições.

Apesar de boa parte dos membros do Conselho ser substituída por motivos de falecimento ou aposentadoria (SANTOS, 1996), outras razões levaram aos afastamentos e trocas de conselheiros. Esse foi o caso do arquiteto Carlos Leão que, em 1938, se afastou do Conselho Consultivo por conta do desentendimento provocado pela vitória do projeto de Oscar Niemeyer para

\footnotetext{
21 Durante o período pesquisado, o Conselho Consultivo tinha em sua composição sete historiadores (quatro nomeados pelo Presidente, três diretores de museus); cinco historiadores da arte (quatro nomeados pelo Presidente, um diretor de museu); quatro artistas (dois nomeados pelo Presidente, dois diretor de museus); quatro arquitetos (os quatro nomeados pelo Presidente); quatro escritores (três diretores de museus, um nomeado pelo Presidente); três antropólogos e uma antropóloga (dois nomeados pelo Presidente, dois diretores de museus); um arqueólogo (nomeado pelo Presidente); um jurista (nomeado pelo Presidente); um naturalista (diretor de museu); e, um zoólogo (diretor de museu). Desse modo, enquanto os nomeados pelo Presidente da República concentravam-se nas ocupações de historiador, historiador da arte, arquiteto e artista; aqueles diretores de museus eram historiador, historiador da arte, artistas, escritores, antropólogos, naturalista, zoólogo.
} 
construção do Grande Hotel na cidade de Ouro Preto. ${ }^{22}$ Por conta disto, Lucio Costa assumiu temporariamente a posição de membro do Conselho o substituindo (CHUVA, 2009). O escritor Eugênio Gomes - integrante do movimento modernista baiano - permaneceu no Conselho apenas por dois anos (1962-1963) e o escritor Thiers Martins Moreira integrou o Conselho igualmente por dois anos (1959-1960), em substituição a Américo Jacobina Lacombe, diretor da Casa de Rui Barbosa, o qual se afastou da função para executar cargos de administração em outras agências. ${ }^{23}$

Houve conselheiros que permaneceram por longos anos no Conselho, para além do recorte cronológico adotado por este artigo, deixando de integrá-lo por conta de falecimento ou um pouco antes de falecer. Dentre eles, destacamse Afonso Arinos, Alfredo Galvão, Américo Jacobina Lacombe, Augusto José Marques Júnior, Edgard Roquette-Pinto, Francisco Marques dos Santos, Gilberto Ferrez, Gustavo Barroso, José Soares de Mello, Miran de Barros Latif, Paulo Santos, Pedro Calmon e Rodolfo Gonçalves de Siqueira.

Márcia Chuva afirma, em sua análise sobre a institucionalização do patrimônio no Brasil nas décadas de 1930 e 1940, que os membros do Conselho Consultivo eram "[...] notórios integrantes dos campos intelectual e político brasileiros. Nesse sentido,entre os atributos que compartilhavam, estava o fato de que todos os seus membros tinham alguma forma de inserção no Estado. [...]" (CHUVA, 2009: 224). Nas décadas subsequentes, delimitadas pelo presente artigo (1938-1966), os integrantes do Conselho Consultivo permaneciam integrando de diferentes maneiras as agências do Estado. Alguns conselheiros ampliaram sua atuação no Sphan ao participarem como autores da Revista do Patrimônio, sobretudo, redigindo artigos sobre a História da Arte. Além disso, o conselheiro Manuel Bandeira publicou, a pedido de Rodrigo Melo Franco de Andrade, em 1938, o Guia de Ouro Preto, passando a ser obra

\footnotetext{
${ }^{22}$ Sobre o Grande Hotel de Ouro Preto, conforme MOTTA, Lia. A SPHAN em Ouro Preto: uma história de conceitos e critérios. Revista do Patrimônio Histórico e Artístico Nacional, n. 22. p. $108-122$.

${ }^{23}$ Américo Jacobina Lacombe, diretor da Casa de Rui Barbosa de 1939 a 1993, afastou-se do cargo em dois momentos: entre 1959 e 1960 para exercer o cargo de Secretário de Educação e Cultura do antigo Distrito Federal e entre 1962 e 1963 com a finalidade de dirigir a Casa do Brasil da Cidade Universitária de Paris.
} 
de referência sobre a cidade (AGUIAR, 2014). Luiz de Castro Faria, interlocutor frequentes de Rodrigo Melo Franco de Andrade, foi um dos principais responsáveis pela legislação de proteção ao patrimônio arqueológico (SIMÃO, 2008). O curso ministrado por Afonso Arinos de Melo Franco, em 1941, nas dependências do Sphan, a pedido de seu primo Rodrigo Melo Franco de Andrade, transformou-se no livro Desenvolvimento da Civilização Material no Brasil, editado na série Publicações do Sphan, em 1944. Consoante Luciano dos Santos Teixeira (2012), a referida publicação “[...] se tornou obra-chave para a compreensão das bases teóricas e metodológicas que subsidiaram a ação do Serviço. [...]" (TEIXEIRA, 2012: 47). O conceito "civilização material", elaborado por Afonso Arinos, consistia na ideia de que “[...] a presença portuguesa predominava sobre as influências negra e indígena, que praticamente não haviam deixado vestígios matérias significativos." (FONSECA, 2009: 107). Tal noção iria nortear a demarcação das manifestações e vestígios da referida "civilização material" pelo território brasileiro (TEIXEIRA, 2012). Foi oferecido ainda o curso Arte Indígena, ministrado pela conselheira Heloísa Alberto Torres, e lançado o livro homônimo, pela série Publicações do Sphan, em 1940.

Além da atuação mais ampla, com a participação na revista e em publicações do Sphan, alguns dos conselheiros eram mais atuantes e solicitados para serem relatores de processos que outros. Com base na tabela em anexo, pode-se visualizar as distintas atuações no Conselho. Pode-se notar, por exemplo, que o historiador da arte Francisco Marques dos Santos participou, no período estudado, de 41 reuniões, tendo relatado apenas quatro processos de tombamento. Ao longo desse tempo, o historiador da arte José Wasth Rodrigues assistiu a apenas seis reuniões do Conselho, mas foi escolhido para relatar três processos. Pode-se citar ainda o caso do artista Augusto José Marques Júnior e do historiador da arte Rodolfo Gonçalves de Siqueira - integraram o Conselho por 20 e 16 anos, respectivamente -, participaram de mais de $50 \%$ das reuniões realizadas no período em que eram conselheiros e não foram escolhidos para relatar qualquer processo. Tais disparidades na escolha de relator de processos 
de tombamento demonstram que, ao longo do período estudado, certamente existiram regras tácitas definidoras de hierarquias dentro do Conselho, as quais diferenciaram os membros com papel determinante e os que apenas possuíam assento nesse órgão colegiado.

Mostra-se notória a escolha de Paulo Santos, Afonso Arinos, Miran Latif e Pedro Calmon com maior frequência para relatores dos processos de tombamento. Conforme tabela em anexo, o arquiteto Paulo Santos, de 1955 a 1966 - período que compreende o início da sua participação no Conselho e o recorte cronológico deste artigo - foi solicitado para relatar 17 processos de tombamento. Afonso Arinos, historiador e membro do Conselho desde 1938, relatou nove processos durante o período pesquisado. $\mathrm{O}$ arquiteto Miran Latif, entre 1946 e 1966, havia sido escolhido como relator de dez processos de tombamento. Enquanto o historiador Pedro Calmon, de 1946 a 1966, relatou oito processos. Os processos relatados pelos citados conselheiros eram de natureza diversa, localizando-se, sobretudo, nos estados do Rio de Janeiro e Minas Gerais. Além de terem sido os conselheiros mais escolhidos como relator durante o período analisado, cabe notar que, conforme se verifica nas atas, eram inegavelmente - principalmente Afonso Arinos e Pedro Calmon - os membros que mais se destacavam nas discussões e na demonstração de interesse quantos aos julgamentos em questão.

Destaca-se, além disso, o discreto papel exercido pelos diretores de museus no Conselho Consultivo. Raramente eram solicitados como relatores de processos de tombamento, mesmo estes tendo mantido considerável frequência nas reuniões do Conselho. Com exceção do diretor do MHN, Gustavo Barroso, que compareceu apenas a nove reuniões - 29\% de frequência - em 31 reuniões realizadas enquanto integrou o Conselho. A despeito disso, julgou dois processos de tombamento, o que se mostra interessante, uma vez que outros diretores bem mais assíduos nunca foram escolhidos como relatores, caso de Oswaldo Teixeira, diretor do MNBA. ${ }^{24}$

\footnotetext{
${ }^{24} \mathrm{O}$ fato de os diretores dos museus não terem destacada participação no Conselho Consultivo não quer dizer que o Sphan, na figura de Rodrigo Melo Franco de Andrade, não tenha traçado estreitos diálogos com esses diretores. Tais relações foram fundamentais para a
} 
A despeito de o Decreto-lei ${ }^{\circ}$ 25/37 definir que as indicações dos dez membros do Conselho Consultivo seriam feitas pelo Presidente da República, pode-se supor que os primeiros membros empossados no Conselho foram proposições de Rodrigo Melo Franco de Andrade. De todo modo, a partir do Regimento Interno de 1946, caberia ao diretor do órgão de preservação propor ao ministro os membros que comporiam o Conselho Consultivo do Sphan (BRASIL, 1967). Com exceção de Afonso Arinos de Melo Franco, os demais integrantes do quarteto mais solicitado do Conselho Consultivo ingressaram após o Regimento Interno do órgão de preservação, ou seja, foram indicações diretas de Rodrigo Melo Franco de Andrade. Cabe ressaltar que mais de 50\% dos processos de tombamento encaminhados ao Conselho Consultivo do Sphan foram relatados por Paulo Santos, Afonso Arinos, Miran Latif e Pedro Calmon.

Portanto, apesar de nos termos da lei não terem sido pensadas hierarquias internas, percebe-se que alguns conselheiros foram notadamente mais solicitados que outros. Desse modo, não obstante existisse uma heterogeneidade de áreas do saber no Conselho Consultivo, em comparação aos quadros técnicos do órgão de preservação, na prática nota-se que as argumentações acerca do tombamento concentraram-se em certos conselheiros, levando a crer que havia regras tácitas dentro do Conselho, segundo as quais alguns membros concentravam mais poder que os demais. Notadamente, dois deles eram arquitetos, sendo Paulo Santos um reconhecido propulsor da arquitetura moderna.

\section{Considerações finais}

A classificação dos conselheiros do Sphan como "detentores de notório saber" demonstra o alto grau de credibilidade conferido a esses agentes e, consequentemente, a força de suas decisões. Ao mesmo tempo, também é possível pensar no reconhecimento, prestígio e distinção em seus campos de 
atuação e instituições que o título de conselheiro do Sphan poderia trazer. A exaltação do "espírito público" e das capacidades técnicas podem ser compreendidas como esforços constantes para construção de uma imagem de um Conselho autônomo e que não sofria influências em suas decisões dos anseios da direção do Sphan, de demais quadros da instituição ou da sociedade civil organizada. A despeito disso, percebe-se que o distanciamento entre Conselho Consultivo e Sphan não aconteceu na prática, uma vez que a maior parte das decisões dos membros do Conselho foi baseada nos pareceres de técnicos e do diretor do órgão. Além disso, Rodrigo Melo Franco de Andrade direcionava deliberações ao indicar os relatores dos processos de tombamento e ao participar, direta ou indiretamente, da relatoria dos processos encaminhados ao Conselho Consultivo.

O fato das decisões do Conselho serem irrevogáveis e determinantes sobre os bens imóveis e conjuntos urbanos que deveriam ser salvos e, consequentemente, sobre os que poderiam ser destruídos, conferiu poder e credibilidade aos seus integrantes. Ser conselheiro do Sphan ratificava suas "ilustres trajetórias" e construía novas significações e redes de sociabilidades para suas atuações profissionais. Apesar de alguns conselheiros nunca terem sido relatores, o fato de serem nomeados como membros do Conselho Consultivo do Sphan já lhes conferiam, no presente e no futuro, prestígio e status.

A partir do que foi analisado e levado em consideração, apreende-se que o grau de importância conferido ao Conselho Consultivo do Sphan para o órgão de preservação mostrou-se indubitável, tanto quando analisado os termos da lei quanto pela distinção que Rodrigo Melo Franco de Andrade, e outros membros do órgão do patrimônio, identificam nos membros conselheiros. Sua heterogeneidade em função da presença de membros de diferentes áreas do saber - aspecto bastante enfatizado pelos estudos sobre preservação que se referem ao Conselho Consultivo - foi realmente significativa se comparada aos quadros técnicos do Sphan. Contudo, observou-se uma série de nuances que relativizam a suposta diversidade de formação e trajetória dos conselheiros, em 
especial destaca-se a presença de um seleto grupo de conselheiros, sistematicamente escolhido por Rodrigo Melo Franco de Andrade para a relatoria dos processos de tombamento em discussão ou mesmo a participação de alguns deles como autores de artigos publicados na Revista do Sphan ou em publicações e demais atividades institucionais. Tais escolhas talvez estivessem baseadas em afinidades temáticas e interpretativas, as quais aproximavam os conselheiros mais solicitados das concepções de patrimônio que estavam sendo moldadas pelos quadros técnicos do órgão de preservação.

A análise das trajetórias profissionais e das redes de relações pessoais e profissionais traçadas pelos conselheiros dentro e fora do Sphan e o refinamento das investigações sobre suas atuações no Conselho Consultivo são tarefas futuras que podem contribuir significativamente para o conjunto de análises já realizadas sobre a formação de um campo do patrimônio cultural no Brasil.

\section{Referências}

AGUIAR, L. B. Projetos nacionais de preservação do patrimônio: promoção, divulgação e turismo nos sítios urbanos patrimonializados durante a gestão de Rodrigo Mello Franco de Andrade. In: MAGALHÃES, A. M.; BEZERRA, R. Z. (Org.). 90 anos do Museu Histórico Nacional. Rio de Janeiro: Museu Histórico Nacional, 2014. p. 187-194.

ANDRADE, R. M. F. de. Rodrigo e seus tempos. Rio de Janeiro: Ministério da Cultura/Fundação Nacional Pró-Memória, 1986.

BENS móveis e imóveis inscritos nos Livros do Tombo do Instituto do

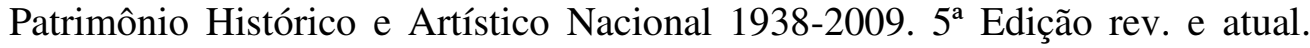
[versão preliminar]. Rio de Janeiro: Ministério da Cultura/ Instituto do Patrimônio Histórico e Artístico Nacional/ CODOC/ COPEDOC/ DAF, 2009.

BOMENY, H. Modernistas mineiros: Guardiões da razão. Rio de Janeiro: UFRJ/Tempo Brasileiro, 1994.

BOMENY, H. Infidelidades eletivas: intelectuais e política. In: BOMENY, H. (Org.). Constelação Capanema: intelectuais e políticas. Rio de Janeiro: Ed. Funfação Getúlio Vargas; Bragança Paulista (SP): Ed. Universidade de São Francisco, 2001. p.11-35. 
BOURDIEU, P. Razões práticas: sobre a teoria da ação. Campinas: Papirus, 1996.

BRASIL. Legislação brasileira de proteção aos bens culturais. Rio de Janeiro: MEC/DPHAN, 1967.

CHAGAS, M. O pai de Macunaíma e o patrimônio espiritual. In: CHAGAS, M; ABREU, R. (orgs.). Memória e Patrimônio: ensaios contemporâneos. Rio de Janeiro: DP\&A, 2003. p. 95-108.

CHUVA, M. Os Arquitetos da Memória: sociogênese das práticas de preservação do patrimônio cultural no Brasil (anos 1930-1940). Rio de Janeiro: Ed.UFRJ, 2009.

CHUVA, M. Patrimônio cultural no Brasil: proteção, salvaguarda e tutela. In: LIMA, A.C.S. (Org.). Tutela: Formação de Estado e tradições de gestão no Brasil. Rio de Janeiro: e-papers, 2014. p. 201-218.

FARIA, L. de C. Nacionalismo, nacionalismos - dualidade e polimorfia: à guisa de depoimento e reflexão. In: CHUVA, M. (Org.). A Invenção do Patrimônio: continuidade e ruptura na constituição de uma política oficial de preservação cultural no Brasil. Rio de Janeiro: IPHAN, 1995. p. 27-40.

FONSECA, M.C.L. O patrimônio em processo: trajetória da política federal de preservação no Brasil. 3. ed. Rio de Janeiro: Editora UFRJ/Iphan, 2009.

GONÇALVES, J.R. A retórica da perda: os discursos do patrimônio cultural no Brasil.Rio de Janeiro: Editora UFRJ/MinC-IPHAN, 1996.

LENZI, M.I. Para aprendermos história sem nos fatigar: a tradição do antiquariado e a historiografia de Gilberto Ferrez.2013, 267p. Tese (Doutorado em História) - Faculdade de História, Universidade Federal Fluminense, Niterói, 2013.

LOWANDE, W. Uma história transnacional da modernidade: produção de sujeitos e objetos da modernidade por meio dos conceitos de civilização e cultura e do patrimônio etnográfico e artístico. 2018, 538p. Tese (Doutorado em História) - Faculdade de História, Universidade Estadual de Campinas, São Paulo, 2018.

MONTENEGRO, A. Colecionando relíquias... Um estudo sobre a Inspetoria de Monumentos Nacionais (1934-1937). 2004, 152p.Dissertação (Mestrado em História Social) - Faculdade de História,Universidade Federal do Rio de Janeiro, Rio de Janeiro, 2004. 
MOTTA, L. O SPHAN em Ouro Preto: uma história de conceitos e critérios. Revista do Patrimônio Histórico e Artístico Nacional, Rio de Janeiro,n. 22, p. 108-122, 1987.

RUBINO, S. As fachadas da história: os antecedentes, a criação e os trabalhos do Serviço do Patrimônio Histórico e Artístico Nacional, 1937-1968. 1991, 206p.Dissertação (Mestrado em Antropologia) - Instituto de Filosofia e Ciências Humanas, Departamento de Antropologia, Universidade Estadual de Campinas, São Paulo, 1991.

RUBINO, S. O mapa do Brasil passado. Revista do Patrimônio Histórico e Artístico Nacional, Rio de Janeiro, n. 24, p. 97-105, 1996.

SANTOS, M.V.M. Nasce a academia Sphan. Revista do Patrimônio Histórico e Artístico Nacional, Rio de Janeiro, n. 24, p. 77-95, 1996.

SERVIÇO DO PATRIMÔNIO HISTÓRICO E ARTÍSTICO NACIONAL (SPHAN). Proteção e revitalização do patrimônio cultural no Brasil: uma trajetória. Brasília: Mec/Sphan/ Pró-memória, 1980.

SILVA NETO, J. O Conselho Consultivo do SPHAN (1938-1966): trajetórias e práticas. 2015, 74p. Trabalho de Conclusão de Curso (Licenciatura em História) - Faculdade de História.,Universidade Federal do Estado do Rio de Janeiro, Rio de Janeiro, 2015.

SILVA NETO, J. Nem tão moderno assim: intelectuais do Conselho Consultivo do Sphan e do IHGB construindo o patrimônio e narrando a história (19381966). 2018, 158p. Dissertação (Mestrado em História Social) - Faculdade de História, Universidade Federal do Estado do Rio de Janeiro, Rio de Janeiro, 2018.

SIMÃO, L. A semântica do intangível. Considerações sobre o registro do ofício de paneleira no Espírito Santo. 2008, 306p.Tese (Doutorado em Antropologia) - Programa de Pós-Graduação em Antropologia, Universidade Federal Fluminense, Rio de Janeiro, 2008.

TEIXEIRA, L. dos S. Civilização material, história e preservação em Afonso Arinos. In: CHUVA, M.; NOGUEIRA, A.G. (Org.). Patrimônio Cultural: políticas e perspectivas de preservação no Brasil. Rio de Janeiro: Mauad/ FAPERJ, 2012.p. 47-56. 
Anexo

Tabela de atuação e participação dos membros do Conselho Consultivo do

Sphan

$(1938-1966)^{25}$

\begin{tabular}{|c|c|c|c|c|c|c|}
\hline $\begin{array}{l}\text { Nome do } \\
\text { conselheiro }\end{array}$ & $\begin{array}{l}\text { Principal } \\
\text { área de } \\
\text { atuação }\end{array}$ & $\begin{array}{l}\text { Período } \\
\text { como } \\
\text { conselheiro }\end{array}$ & $\begin{array}{c}\mathrm{N}^{o} \text { de reuniões no } \\
\text { período como } \\
\text { conselheiro }\end{array}$ & $\begin{array}{c}\mathrm{N}^{\mathrm{o}} \text { reuniões } \\
\text { comparecida } \\
\mathrm{S}\end{array}$ & $\begin{array}{l}\text { Frequência } \\
\text { em } \\
\text { porcentagem }\end{array}$ & $\begin{array}{l}\mathrm{N}^{\circ} \mathrm{de} \\
\text { processos } \\
\text { relatados }\end{array}$ \\
\hline $\begin{array}{l}\text { Afonso Arinos } \\
\text { de Melo Franco }\end{array}$ & Historiador & $1938-1987$ & 50 reuniões & 34 reuniões & $68 \%$ & 9 \\
\hline $\begin{array}{l}\text { Alberto Childe } \\
\text { (DmitriVonizin) }\end{array}$ & $\begin{array}{c}\text { Arqueologi } \\
\text { a }\end{array}$ & $1938-1949$ & 17 reuniões & 4 reuniões & $24 \%$ & 2 \\
\hline $\begin{array}{l}\text { Alcindo de } \\
\text { Azevedo Sodré }\end{array}$ & Historiador & $1940-1952$ & 7 reuniões & 5 reuniões & $71 \%$ & Nenhum \\
\hline Alfredo Galvão & $\begin{array}{l}\text { Historiador } \\
\text { da Arte }\end{array}$ & $1958-1984$ & 23 reuniões & 21 reuniões & $91 \%$ & 5 \\
\hline $\begin{array}{l}\text { Américo } \\
\text { Jacobina } \\
\text { Lacombe }\end{array}$ & Historiador & 1947-1992 & 35 reuniões & 19 reuniões & $54 \%$ & 4 \\
\hline $\begin{array}{l}\text { Antônio } \\
\text { Joaquim } \\
\text { Andrade de } \\
\text { Almeida }\end{array}$ & $\begin{array}{l}\text { Historiador/ } \\
\text { Museólogo }\end{array}$ & 1966-1966 & 1 reunião & 1 reunião & $100 \%$ & Nenhum \\
\hline $\begin{array}{l}\text { Augusto José } \\
\text { Marques Junior }\end{array}$ & Artista & $1938-1957$ & 25 reuniões & 14 reuniões & $56 \%$ & Nenhum \\
\hline $\begin{array}{l}\text { Carlos de } \\
\text { Azevedo Leão }\end{array}$ & Arquiteto & $1938-1938$ & 5 reuniões & 5 reuniões & $100 \%$ & 3 \\
\hline $\begin{array}{l}\text { Edgar Roquette- } \\
\text { Pinto }\end{array}$ & $\begin{array}{c}\text { Antropólog } \\
\text { o }\end{array}$ & $1938-1954$ & 18 reuniões & 8 reuniões & $44 \%$ & 2 \\
\hline Eugênio Gomes & Escritor & $1962-1963$ & 4 reuniões & 4 reuniões & $100 \%$ & 1 \\
\hline $\begin{array}{l}\text { Francisco } \\
\text { Marques dos } \\
\text { Santos }\end{array}$ & $\begin{array}{l}\text { Historiador } \\
\text { da Arte }\end{array}$ & $1938-1975$ & 50 reuniões & 41 reuniões & $82 \%$ & 4 \\
\hline Gilberto Ferrez & Historiador & 1958-1997 & 23 reuniões & 20 reuniões & $87 \%$ & 3 \\
\hline Gustavo Barroso & Historiador & 1938-1959 & 31 reuniões & 9 reuniões & $29 \%$ & 2 \\
\hline $\begin{array}{l}\text { Heloísa Alberto } \\
\text { Torres }\end{array}$ & $\begin{array}{c}\text { Antropólog } \\
\text { a }\end{array}$ & $1938-1955$ & 19 reuniões & 13 reuniões & $68 \%$ & 1 \\
\hline $\begin{array}{l}\text { José Cândido de } \\
\text { Mello Carvalho }\end{array}$ & Zoólogo & $1955-1961$ & 17 reuniões & 11 reuniões & $65 \%$ & 2 \\
\hline
\end{tabular}

${ }^{25}$ Esta tabela teve como base as atas do Conselho Consultivo do Sphan, disponíveis em: $<$ http://portal.iphan.gov.br/atasConselho>. Nota-se que, no caso dos membros diretores de museus, adotou-se a permanência conforme a data que estes tomaram posse e desempossaram do cargo. Desse modo, cabe a observação que Newton Dias dos Santos, diretor do Museu Nacional entre 1961 e 1964, compareceu a uma única reunião do Conselho em 1965, momento em que, conforme os documentos apontam, não era mais membro do Conselho Consultivo. SILVA NETO, Jamile. O Conselho Consultivo do SPHAN (1938-1966): trajetórias e práticas. Trabalho de Conclusão de Curso (Licenciatura em História) - Universidade Federal do Estado do Rio de Janeiro, Rio de Janeiro, 2015. 
AGUIAR, L. B.\& NETO, J. S. 231

\begin{tabular}{|c|c|c|c|c|c|c|}
\hline $\begin{array}{l}\text { José Otávio } \\
\text { Corrêa Lima }\end{array}$ & Artista & $1938-1974$ & 50 reuniões & 26 reuniões & $52 \%$ & 1 \\
\hline $\begin{array}{l}\text { José Roberto } \\
\text { Teixeira Leite }\end{array}$ & $\begin{array}{c}\text { Historiador } \\
\text { da Arte }\end{array}$ & $1961-1964$ & 7 reuniões & 4 reuniões & $57 \%$ & Nenhum \\
\hline $\begin{array}{l}\text { José Soares de } \\
\text { Mello }\end{array}$ & Jurista & $1955-1971$ & 32 reuniões & 19 reuniões & $59 \%$ & 5 \\
\hline $\begin{array}{l}\text { José Wasth } \\
\text { Rodrigues }\end{array}$ & $\begin{array}{c}\text { Historiador } \\
\text { da Arte }\end{array}$ & $1953-1957$ & 6 reuniões & 6 reuniões & $100 \%$ & 3 \\
\hline $\begin{array}{l}\text { Josué de Souza } \\
\text { Montello }\end{array}$ & Escritor & $1960-1967$ & 19 reuniões & 12 reuniões & $63 \%$ & 1 \\
\hline Lucio Costa & Arquiteto & $1938-1940$ & 6 reuniões & 4 reuniões & $67 \%$ & 1 \\
\hline $\begin{array}{l}\text { Luiz de Castro } \\
\text { Faria }\end{array}$ & $\begin{array}{c}\text { Antropólog } \\
\text { o }\end{array}$ & 1964-1967 & 5 reuniões & 4 reuniões & $80 \%$ & 1 \\
\hline $\begin{array}{l}\text { Manuel } \\
\text { Constantino } \\
\text { Gomes Ribeiro }\end{array}$ & Artista & $1961-1961$ & 3 reuniões & 3 reuniões & $100 \%$ & Nenhum \\
\hline $\begin{array}{l}\text { Manuel } \\
\text { Bandeira }\end{array}$ & Escritor & $1938-1968$ & 50 reuniões & 39 reuniões & $78 \%$ & 2 \\
\hline $\begin{array}{l}\text { Miran de Barros } \\
\text { Latif }\end{array}$ & Arquiteto & $1946-1968$ & 39 reuniões & 31 reuniões & $79 \%$ & 10 \\
\hline $\begin{array}{l}\text { Newton Dias } \\
\text { dos Santos }\end{array}$ & Naturalista & $1961-1964$ & 6 reuniões & 3 reuniões & $50 \%$ & Nenhum \\
\hline $\begin{array}{l}\text { Oswaldo } \\
\text { Teixeira }\end{array}$ & Artista & $1938-1961$ & 39 reuniões & 23 reuniões & $59 \%$ & Nenhum \\
\hline $\begin{array}{l}\text { Paulo Ferreira } \\
\text { dos Santos }\end{array}$ & Arquiteto & $1955-1980$ & 32 reuniões & 30 reuniões & $94 \%$ & 17 \\
\hline Pedro Calmon & Historiador & 1946-1985 & 39 reuniões & 26 reuniões & $67 \%$ & 8 \\
\hline $\begin{array}{l}\text { Raimundo } \\
\text { Lopes da Cunha }\end{array}$ & $\begin{array}{c}\text { Antropólog } \\
\text { o }\end{array}$ & $1938-1940$ & 11 reuniões & 10 reuniões & $91 \%$ & 3 \\
\hline $\begin{array}{l}\text { Rodolfo } \\
\text { Gonçalves de } \\
\text { Siqueira }\end{array}$ & $\begin{array}{c}\text { Historiador } \\
\text { da Arte }\end{array}$ & $1938-1953$ & 19 reuniões & 14 reuniões & $74 \%$ & Nenhum \\
\hline $\begin{array}{l}\text { Sérgio Ferreira } \\
\text { da Cunha }\end{array}$ & Museólogo & $1960-1960$ & 1 reunião & 1 reunião & $100 \%$ & Nenhum \\
\hline $\begin{array}{l}\text { Thiers Martins } \\
\text { Moreira }\end{array}$ & Escritor & $1959-1960$ & 4 reuniões & 3 reuniões & $75 \%$ & Nenhum \\
\hline
\end{tabular}

Recebido em: 6 de maio de 2019

Aceito em: 29 de outubro de 2019 